\title{
FONTES INSTRUMENTAIS E DOCUMENTAIS PARA A RECONSTRUÇÃO DO CLIMA DO PASSADO DEBATIDAS EM CONFERENCIA INTERNACIONAL
}

\author{
MARIA JoÃo AlCOFORADO ${ }^{1}$
}

As alterações climáticas são actualmente motivo de preocupação de cientistas, de cidadãos e também dos políticos de todo o mundo. As mais recentes alterações do clima são relativamente bem conhecidas. No entanto, no sinal detectado desde o início das observações regulares, conjugam-se causas naturais e outras devidas ao Homem e às suas actividades.

Para melhor se conseguir prever o futuro, é necessário isolar as causas naturais das alterações climáticas. Tal é possível analisando o período anterior à era industrial, ou seja, antes de instalada a maior parte das estações meteorológicas fornecedoras de dados instrumentais. Foi em Itália, que as observações regulares se iniciaram mais cedo, poucas décadas depois da invenção e aperfeiçoamento de aparelhos meteorológicos como o termo-baroscópio de Galileu, em 1593, o pluviómetro e evaporímetro de Castelli, em 1639, o barómetro de Torricelli, em 1643 (Camuffo, 2002). As séries mais antigas nem sempre são contínuas, nem homogéneas, tendo sido interrompidas frequentemente, por vezes devido a perseguições da Inquisição (Camuffo, 2002). Em Portugal, existem alguns dados referentes ao século XVIII e primeira parte do XIX, apresentadas e analisadas em Taborda et al. (2004), Alcoforado et al. (1999), Barriendos et al. (2000) e incluídos em Jones et al. (1999).

A comunidade científica compreendeu a importância de recuar no tempo no conhecimento do clima do passado para, por um lado, entender mais objectivamente as causas naturais das alterações climáticas e, por outro, prever com maior acuidade o clima futuro, tendo também em conta as causas antrópicas. Daí nasceu o projecto Millennium (http:// geography.swansea.ac.uk/millennium) com um objectivo claro: “determinar com precisão quantificada se a magnitude e a taxa de alteração climática durante o século XX, excederam a variabilidade natural do clima europeu durante o último milénio" (tradução de http://geography.swansea.ac.uk/millennium/Millennium3a.htm).

A metodologia de base consiste em combinar diversos dados obtidos de fontes antrópicas (documentais ou instrumentais) e naturais para desenvolver modelos de alteração climática do passado. Neste projecto, participam 39 instituições, tendo os investigadores formação muito diversa: biólogos, físicos, geógrafos, historiadores, meteorologistas, entre outros, além de 17 "cientistas colaboradores" de outras tantas instituições, incluindo

1 Investigadora do Centro de Estudos Geográficos da Universidade de Lisboa e Professora Catedrática do Departamento de Geografia da FLUL. Email: mjalc@fl.ul.pt 
o Centro de Estudos Geográficos da Universidade de Lisboa. O projecto está dividido em cinco subgrupos, quatro encarregues de explorar diferentes tipos de fontes: arquivos instrumentais e documentais (sub-grupo 1 - SG1 - que se referirá à frente), anéis de crescimento das árvores (SG2), sedimentos terrestres (SG3) e sedimentos marinhos (SG4); o quinto sub-grupo tem a missão de recolher e analisar os dados e levar a cabo a elaboração dos modelos e a síntese geral. Dar-se-á conta dos trabalhos do primeiro grupo.

No seguimento da investigação de Emmanuel Le Roy Ladurie, nomeadamente da conhecida obra "Histoire du climat depuis l'an 1000", tem sido Christian Pfister (Historiador na Universidade de Berna) o grande dinamizador dos estudos de climatologia histórica, a partir de dados documentais. Estes foram objecto de discussão no Analytical Workshop on Instrumental and Documentary data in the climate reconstruction of the past millennium in Europe, que teve lugar entre 28 e 31 de Agosto de 2007, na cidade alemã de Freiburg in Breisgau, organizado por R. Glaser. O seminário prolongou-se por mais um dia numa conferência do sub-grupo 1 do já referido projecto Millennium. Participaram 54 pessoas de diversas nacionalidades europeias, tendo sido apresentadas trinta e duas comunicações orais e onze sob a forma de painel. Foram convidados jovens investigadores, com o objectivo de divulgar este tema. A presença dos maiores especialistas nesta matéria, desde o já citado Christian Pfister, a Rudolf Brázdil, Dennis Wheeler, Rüdiger Glaser, Dario Camuffo e Jürg Luterbacher, entre tantos outros, tornou muito interessantes e proveitosas as discussões, que prosseguiram em diversas actividades sociais.

Mais do que fazer um relato sequencial das diversas comunicações, será apresentado um breve resumo das mesmas, ilustrado com alguns exemplos. A maior parte do tempo foi dedicada ao confronto de fontes e sua análise crítica.

As comunicações foram agrupadas em dois grandes grupos: as que tratavam de dados instrumentais e as dirigidas às fontes documentais.

No caso das fontes instrumentais, foram apresentadas comunicações referentes às séries mais longas (italianas, república Checa, Paris, Sul de Inglaterra, Alemanha). A reconstituição de séries homogéneas apresenta inúmeras dificuldades, devido à ausência de metadata, ou seja, informação que deveria acompanhar as tabelas de valores numéricos e dar indicações sobre o tipo de aparelhos e de abrigos utilizados, a localização exacta da estação meteorológica e dos aparelhos nos diversos períodos, etc.

Em grande parte das comunicações, discutiu-se a informação retirada de documentos muito distintos, particularmente as fontes indirectas, ou seja, documentos produzidos com outras finalidades, onde se encontram referências ao estado do tempo e ao clima, datadas e espacialmente referenciadas. Estas últimas podem ser institucionais ou individuais. Como exemplo de fontes institucionais, foram repetidamente tratadas fontes administrativas (em que se incluem as eclesiásticas). Têm a vantagem de, no geral, serem produzidas com regularidade, de raramente terem lacunas e de possuírem grande fiabilidade. Foram apresentados exemplos de informação retirada de Actas das reuniões da Câmara Municipais e de Minutas de Catedrais, bastante utilizadas em Portugal e Espanha (Alcoforado et al, 2000, Alcoforado, 1999, Taborda et al., 2004, Brázdil et al., 2005) e no Reino Unido. Deste país, citem-se os Manorial accounts of Norwich Cathedral Priory, que permitiram reconstituir 22 séries referentes a Norfolk. Nestes documentos, a indicação anual da data de início da colheita dos diversos cereais é usado como indicador da evolução temporal da temperatura no fim da Primavera e no início do Verão. De entre outras fontes documentais, foram apresentados exemplos de utilização de diários de bordo, muito ricos em descrições de acontecimentos meteorológicos extremos, de notícias extraídas de jornais sobre cheias na Morávia e Silésia, de 1851 até 1900 e de dados instrumentais publicados 
em jornais de Brno (desde 1848) e de Lisboa (desde 1818) e em calendários astronómicos (informação hidro-meteorológica para Cracóvia).

As fontes individuais podem ser - e têm sido - utilizadas com êxito, desde que se conheça a biografia dos autores, que devem ser contemporâneos dos acontecimentos e o ambiente sócio-cultural em que se movimentaram. Foram sobretudo tratados os "diários meteorológicos" em que, dia após dia, eram registados o estado do tempo e os episódios meteorológicos extremos. De entre os exemplos apresentados, a maior parte ainda em estudo, citam-se: os diários escritos em Hamar, na Noruega oriental (1749-1835), diários de agricultores, também na Noruega, que se referiam anualmente, desde 1758, à data em que a fusão do gelo possibilitava a chegada dos navios ao litoral SE do país, permitindo a reconstrução da temperatura entre Fevereiro e Abril e, ainda, um diário meteorológico para a Polónia (1656-1667).

No final teve lugar uma série de comunicações, em que foi dada ênfase às técnicas de calibração e validação das séries reconstruídas, a qual é relativamente fácil quando existe um período comum de dados instrumentais e documentais. Foram sugeridas metodologias para a calibração de séries, quando tal não acontece.

Muitos dos trabalhos apresentados nesta conferência irão ser submetidos a revistas internacionais, completando a informação divulgada no excelente artigo de síntese de Brázdil et al. (2005). Está a ser preparado um número temático da revista Climatic Change sobre climatologia histórica, fazendo o ponto da situação sobre a reconstrução climática a partir de fontes documentais na Europa nos últimos 500 anos tentando também apreender a vulnerabilidade das diferentes sociedades aos acontecimentos meteorológicos extremos.

\section{BIBLIOGRAFIA}

Alcoforado M J, Nunes M F, Garcia J C, Taborda J P (2000) Temperature and precipitation reconstruction in southern Portugal during the late Maunder Minimum (AD 1675-1715). The Holocene, 10(3): 333-340.

Alcoforado M J, Nunes M F, Garcia R (1999) A percepção da relação clima-saúde pública em Lisboa, no século XIX, através da obra de Marino Miguel Franzini. Revista Portuguesa de Saúde Pública, 17(2): 31-40.

Alcoforado M J (1999) Variações climáticas do passado: chave para o entendimento do presente? Territorium, 6: 19-30.

Barriendos M, Garcia J C, Martín-Vide J, Nunes F, Peña J C, Alcoforado M J (2000) $18^{\text {th }}$ Century instrumental meteorological series in the Iberian Peninsula. General characteristics and climatic utility. In Pigato L (ed.) Giuseppe Toaldo e il suo Tempo (1719-1797): 907-920.

Brázdil R, Pfister C, Wanner H, V. Storch H, Luterbacher J (2005) Historical climatology in Europe - the state of the art. Climatic Change, 70: 363-430.

Camuffo D (2002) History of the long series of daily air temperature in Padova (1725ñ1998). Climatic Change, 53: 7-75.

Jones P D e 21 co-autores (1999) Monthly mean pressure reconstruction for Europe for the 1780-1995 period. International Journal of Climatology, 19(4): 347-364.

Taborda J P, Alcoforado M J, Garcia J C (2004) O clima do Sul de Portugal no século XVIII - reconstituição a partir de fontes descritivas e instrumentais. Geo-Ecologia, 2, Centro de Estudos Geográficos, Lisboa. 